\title{
Rancangan Bangun Turbin Mikrohidro Tipe Archimedes Screw Dengan Kapasitas Daya 560 Watt
}

\author{
Zainuri Anwar ${ }^{1}$, Beta Saud Parsaroan ${ }^{1}$, Edi Sunarso ${ }^{1}$ \\ ${ }^{1}$ Jurusan Teknik Mesin, Sekolah Tinggi Teknologi Nasional Jambi \\ *Corresponding author, e-mail: zzainurianwar@gmail.com
}

\begin{abstract}
Abstrak. Kinerja sebuah turbin mikrohidro dipengaruhi oleh beberapa faktor yaitu proses perancangan dan lingkungan. Penelitian ini bertujuan untuk mendapatkan parameter desain yang tepat untuk pembuatan turbin ulir (screw). Rancangan difokuskan pada dimensi sudu dan jarak pitch turbin screw. Perhitungan dilakukan menggunakan beberapa formulasi ketetapan turbin ulir. Hasil desain menunjukkan bahwa diameter sudu dan jarak pitch turbin yang optimum masing - masing berkisar 0,213 m dan 0,312 m pada debit air masuk turbin $0,2 \mathrm{~m}^{3} / \mathrm{s}$ dan daya keluaran poros turbin 563,3 Watt. Pengujian turbin screw hasil rancangan dilakukan di aliran sungai Perumahan Puri Kedaton Desa Pematang Gajah Rt 13 provinsi Jambi. Hasil pengujian menunjukkan bahwa daya turbin tertinggi terjadi pada pembebanan poros $30 \mathrm{~kg}$ dengan daya keluaran turbin sebesar 445 Watt dan efisiensi 78,9\%.
\end{abstract}

Kata Kunci: Turbin screw; Daya; dan Effisiensi

\begin{abstract}
The performance of a micro-hydro turbine was influenced by several factors, namely the design and the enviromental. This study aims to obtain the appropriate design parameters for the manufacture of screw turbines. This research was focused on blade dimensions and turbine screw pitch distance. The calculations were performed using several screw turbine fixing formulations. The design results show that the optimum blade diameter and turbine pitch range are $0.213 \mathrm{~m}$ and $0.312 \mathrm{~m}$ at $0.2 \mathrm{~m}^{3}$ I s of turbine inlet water flow and 563.3 Watt turbine shaft output power. The turbine screw test results of the design were carried out in the river flow of Puri Kedaton Housing, Pematang Gajah Village, Rt 13, Jambi Province. The test results show that the highest turbine power occurs at $30 \mathrm{~kg}$ shaft loading with a turbine output power of 445 Watts and an efficiency of $78.9 \%$.
\end{abstract}

Keywords: Screw turbine; Power; and Efficiency

\section{PENDAHULUAN}

Kosumsi energi fosil yang semakin besar membuat ketersediaan akan energy fosil di Indonesia khususnya di provinsi Jambi semakin lama semakin habis. Hal ini mendorong beberapa peneliti untuk beralih ke energy terbarukan yang ramah lingkungan. Kondisi ini diperkuat dengan Peraturan Daerah 2019 tentang pengelolaan energi daerah dengan mempertimbangkan potensi energi daerah, kebutuhan dan penyediaan energi dengan meningkatkan pemanfaatan energi baru terbarukan (EBT).

Perkembangan energi terbarukan di provinsi Jambi masih tergolong sedikit, salah satu upaya untuk meningkatkan EBT tersebut adalah dengan memanfaatkan potensi aliran sungai sebagai sumber energi potensial Pembangkit Listrik Tenaga Mikrohidro (PLTMH) [1]. Daerah aliran sungai (DAS) di provisi jambi berpotensi menghasilkan energi listrik melalui pembangkit mikrohidro. Menurut survei diketahui bahwa aliran daerah aliran sekitar sungai batanghari memiliki kecepatan aliran dan debit yang berpotensi untuk aplikasi PLTMH jenis turbin screw [2].

Turbin Archimedes screw merupakan salah satu jenis turbin yang memiliki efisiensi tinggi yang dapat beroprasi pada head rendah dan juga pada debit air yang besar [3] [4]. Turbin ini pertama kali ditemukan oleh ilmuan yang bernama Archimedes. Turbin Archimedes screw mempunyai sudu yang membentuk helix disekitar poros slinder dan ditutup dengan cover semi melingkar
[5], sehingga ekosistem yang berada di sungai seperti ikan tidak terganggu ketika melewati sudu turbin[6]. Daya output yang dihasilkan dari turbin screw tergantung pada geometri turbin. Terdapat dua parameter yang mempengaruhi geometri yaitu parameter eksternal seperti panjang turbin, radius luar, dan kemiringan, serta parameter internal seperti jari - jari sudu , jumlah dan jarak sudu [7][8][9].

Dari permasalahan diatas dibutuhkan beberapa parameter rancangan yang optimal sehingga efisiensi turbin screw menjadi meningkat.

a) . Daya hidrolis.

Daya yang dihasilkan turbin bergantung dengan energi yang masuk ke turbin, sehingga dalam perancangan turbin ulir perlu diketahui daya hidrolis dengan persamaan [10]:

$\mathrm{P}_{\mathrm{air}}=\rho \mathrm{g} \mathrm{QH}$

Dimana : $\mathrm{P}_{\text {air }}=$ Daya hidrolis air (watt)

$$
\begin{aligned}
& \rho=\text { Massa jenis air }\left(\mathrm{kg} / \mathrm{m}^{3}\right) \\
& \mathrm{Q}=\text { Debit air }\left(\mathrm{m}^{3} / \mathrm{s}\right) \\
& \mathrm{H}=\operatorname{Ketinggian}(\mathrm{m})
\end{aligned}
$$

b) Dimensi turbin screw

Effisiensi turbin screw yang optimum didapatkan dengan mempertimbangkan dimensi turbin dan bahan bahan yang digunakan dalam proses manufaktur. Penentuan dimensi ini ditinjau dari nilai effisiensi tertinggi turbin yang dapat dilihat pada table optimasi turbin screw yaitu: 
Tabel 1. Optimasi turbin screw

\begin{tabular}{ll}
\hline Perbandingan diameter d/D & 0,3 \\
Sudut ulir $(\alpha)$ & 30 \\
Sudut turbin $(\alpha)$ & 30 \\
\hline
\end{tabular}

\section{Dimensi diameter scew}

Dari persamaan Archimedes screw [7] diperoleh dimensi ulir :

$\mathrm{Q}=\mathrm{k} \cdot \mathrm{n} \cdot \mathrm{D}^{3}$

Dimana : $\mathrm{Q}=$ Debit air $\left(\mathrm{m}^{3} / \mathrm{s}\right)$

$$
\begin{aligned}
& \mathrm{k}=\text { Konstanta turbin } \\
& \mathrm{n}=\text { Putaran turbin }(\mathrm{rpm}) \\
& \mathrm{D}^{3}=\text { Diameter sudu }(\mathrm{m})
\end{aligned}
$$

Dimana nilai konstanta ulir didapat dari table konstanta ulir dan putaran turbin dipilih dari table putaran oprasi turbin screw. putaran turbin screw untuk katagori fast berkisar antara 29-31 rpm.

Tabel 2. Nilai Konstanta Ulir [7]

\begin{tabular}{clllll}
\hline $\mathrm{d} / \mathrm{D}$ & \multicolumn{3}{c}{$26^{\circ}$} & \multicolumn{3}{c}{$30^{\circ}$} \\
\hline & $0,8 \mathrm{D}$ & $1,0 \mathrm{D}$ & $1,2 \mathrm{D}$ & $0,8 \mathrm{D}$ & $1,0 \mathrm{D}$ \\
0,3 & 0,274 & 0,287 & 0,286 & 0,246 & 0,245 \\
0,4 & 0,285 & 0,317 & 0,323 & 0,262 & 0,271 \\
0,5 & 0,281 & 0,317 & 0,343 & 0,319 & 0,287 \\
0,6 & & 0,3 & 0,327 & & 0,273 \\
\hline
\end{tabular}

$\mathrm{d} / \mathrm{D}$ merupakan perbandingan diameter poros turbin terhadap diameter sudu turbin. Jika sudut ulir $30^{\circ}$ maka jarak pitch turbin $(S)=1,2 \mathrm{D}$. sehingga diameter sudu turbin diperoleh:

$D=\sqrt[3]{\frac{Q}{k \cdot n}}$

\section{Dimensi diameter poros turbin}

Untuk perbandingan diameter poros turbin terhadap poros sudu telah ditentukan yaitu :

$$
\frac{d}{D}=0,3
$$

3. Dimensi panjang turbin

Panjang turbin didapat dari sudut poros turbin dan tinggi jatuh air, sehingga didapat persamaan:

$L=\sqrt{H^{2} \cdot a^{2}}$

Dimana : $\mathrm{L}=$ Panjang turbin $(\mathrm{m})$

$$
\begin{aligned}
& \mathrm{H}=\text { Ketinggian }(\mathrm{m}) \\
& \mathrm{a}=\text { Panjang alas turbin }(\mathrm{m})
\end{aligned}
$$

\section{Pitch turbin}

Untuk menentukan pitch turbin terlebih dahulu menetapkan sudut turbin [7].

Jika sudut turbin $\leq 30^{\circ}$ maka $\mathrm{S}=1,2 \mathrm{D}$

Jika sudut turbin $=30^{\circ}$ maka $S=1,0 \mathrm{D}$

Jika sudut turbin $\geq 30^{\circ}$ maka $\mathrm{S}=0,8 \mathrm{D}$

5. Jumlah ulir

$$
Z=\frac{L}{S}
$$

Dimana : $\mathrm{Z}=$ Jumlah ulir

$$
\begin{aligned}
& \mathrm{L}=\text { Panjang turbin }(\mathrm{m}) \\
& \mathrm{S}=\operatorname{Jarak} \text { pitch }(\mathrm{m})
\end{aligned}
$$

6. Effisiensi turbin

$$
\eta=\left(\frac{2 \cdot \alpha+1}{2 \cdot \alpha+2}\right) \cdot\left(1-\frac{0,1125 \cdot D^{2}}{Q}\right)
$$

Dimana : $\alpha=\frac{h_{0}}{\Delta h}$

$$
\begin{aligned}
& \Delta h=X \sin \theta \\
& X=\frac{1}{N} \\
& \mathrm{~N}=\text { Jumlah ulir }
\end{aligned}
$$

\section{METODE}

a) Sekema perancangan turbin

Pada proses perancangan turbin screw terlebih dahulu membuat sekema gambar untuk mempermudahkan alur perancangan turbin.

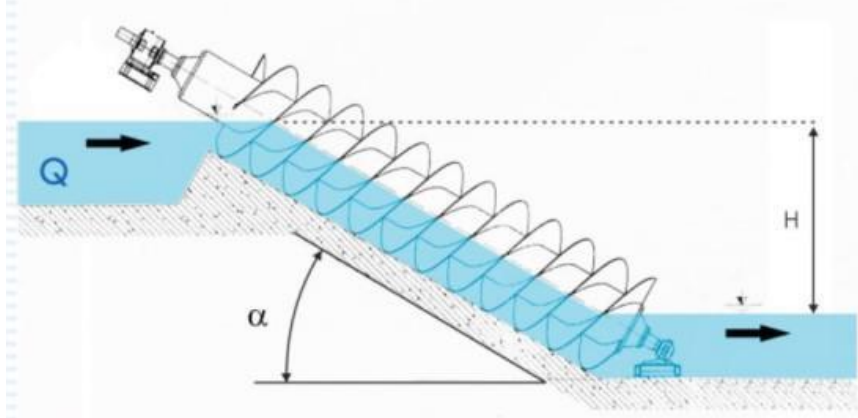

Gambar 1. Sekema perancangan turbin screw

b) proses perancangan

Proses perancangan diawali dengan survey potensi debit air di sungai desa Pematang Gajah Rt 13 untuk menentukan daya rencana turbin screw, sehingga dapat diketahui daya hidrolis dengan persamaan:

$\mathrm{P}=\rho \mathrm{g} \mathrm{QH}$

1. perancangan dimensi screw

screw dihitung berdasarkan daya turbin dan debit air yang telah direncanakan.

2. Perancangan dimensi panjang turbin

Panjang turbin screw didapat dari ketinggian head dan kemiringan turbin screw yang dipilih berdasarkan table optimasi turbin. Pada penelitian ini dipilih sudut turbin $30^{\circ}$ dengan perbandingan diameter poros terhadap sudu 0,3 .

\section{Perancangan jumlah sudu ulir turbin}

Jumlah sudu ulir dirancang berdasarkan panjang turbin yang sudah diketahui yang dibandingkan terhadap jarak pitch turbin. Pitch turbin dipilih 1,2 D

\section{Perancangan transmisi dan cover turbin}

Perancangan transmisi terkait dengan spesifikasi generator yang dipkai, sehingga dalam pemilihan dimeter pulley yang digunakan dapat disesuaikan. Sedangkan untuk cover dari screw turbin menyesuaikan dari diameter screw dan bahan material yang akan dipakai.

c) Proses pembuatan

Pembuatan prototype turbin dilakukan di laboraturium teknik mesin Sekolah Tinggi Teknologi 
Nasional Jambi. Dimensi komponen turbin dibuat sesuai dengan hasil perancangan. Material sudu turbin, poros dan cover dibuat menggunakan bahan plastik PVC, sedangkan untuk rangka turbin dibuat dari bahan baja holo st 37.

d) Proses pengujian

Pengujian turbin screw dilakukan di aliran sungai Perumahan Puri Kedaton Desa Pematang Gajah Rt 13 provinsi Jambi. Sungai tersebut memiliki kecepatan aliran $2.32 \mathrm{~m} / \mathrm{s}$ diukur menggunakan metode manual benda apung yang mengalir dan dikonversi menggunakan jarak per waktu tempuh, sedangkan sungai tersebut memiliki lebar berkisar $2 \mathrm{~m}$ dan kedalaman air $0,3 \mathrm{~m}$.

Pengujian daya poros turbin dilakukan dengan mengetahui torsi poros turbin. Torsi diperoleh dengan memberikan gaya pembebanan pada poros menggunakan neraca pegas. Pembebanan poros pada penelitian ini divariasikan $30 \mathrm{~kg}, 40 \mathrm{~kg}$, dan $50 \mathrm{~kg}$. skema pengujian torsi turbin dapat diihat pada gambar .

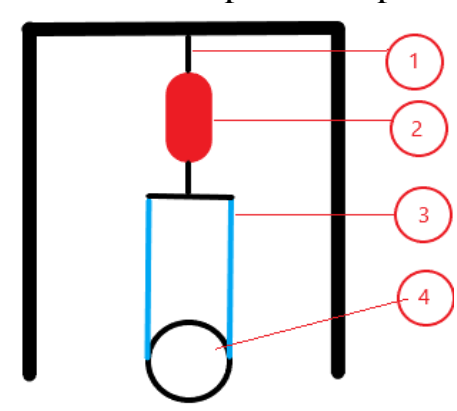

Ket:

\section{Pengatur gaya} pembebanan.

2. Neraca pegas

3. Sabuk

4. Poros turbin

Gambar 2. Skema pengujian torsi

\section{HASIL DAN PEMBAHASAN}

\section{Perhitungan daya rencana}

Daya potensial air yang tersedia tidak semua dimanfaatkan sebagai sumber energi yang masuk ke turbin untuk menghindari ketika sumber air berkurang pada pergantian musim. Sehingga air yang masuk ke turbin diatur melewati kanal (tunnel) dengan dimensi kanal sbb:
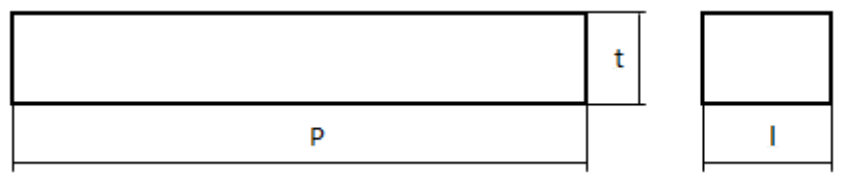

Gambar 3. Dimensi kanal (tunnel)

Dimana diketahui:

$$
\begin{aligned}
& \text { p: } 2000 \mathrm{~mm} \\
& \mathrm{t}: 300 \mathrm{~mm} \\
& 1: 300 \mathrm{~mm} \\
& \text { Hasil survey lokasi } \\
& \text { kecepatan aliran sungai } 2, \\
& \text { air yang melewati kanal: } \\
& \quad Q=V \times A \\
& Q=2,32 \frac{\mathrm{m}}{\mathrm{s}} \times 0,09 \mathrm{~m}^{2}
\end{aligned}
$$$$
\text { Hasil survey lokasi sungai dimana diketahui }
$$
kecepatan aliran sungai $2,32 \mathrm{~m} / \mathrm{s}$ sehingga didapat debit

$$
Q=0,2 \mathrm{~m}^{3} / \mathrm{s}
$$

Dimana daya hidrolis yang melewati kanal:

$$
\begin{aligned}
\mathrm{P}_{\mathrm{h}} & =\rho \mathrm{g} \mathrm{Q} \mathrm{H} \\
& =998 \mathrm{~kg} / \mathrm{m}^{3} \cdot 9,8 \mathrm{~m} / \mathrm{s}^{2} \cdot 0,2 \mathrm{~m}^{3} / \mathrm{s} .0,3 \mathrm{~m} \\
& =612,6 \text { Watt. }
\end{aligned}
$$

2. Diameter screw

$$
\begin{aligned}
& D=\sqrt[3]{\frac{Q}{k \cdot n}} \\
& D=\sqrt[3]{\frac{0,2 \frac{m^{3}}{s}}{0,343.30 r p m}} \\
& D=0,26 m
\end{aligned}
$$

Nilai konstanta dan putaran turbin diambil dari table 2 . Diameter screw dibuat berdasarkan pemilihan diameter cover yang mendekati perhitungan sehingga diameter cover dipilih 10 inch dan jarak antara sudu dan cover 2 $\mathrm{cm}$, maka diameter sudu menjadi $21,54 \mathrm{~cm}$

\section{Diameter poros turbin}

$\frac{d}{D}=0,3$

$d=0,26 m \cdot 0,3$

$d=0,078 \mathrm{~m}$

\section{Panjang turbin}

Panjang turbin dihitung berdasarkan tinggi jatuh air (head) dan kemiriringan turbin dipilih dari beberapa penelitian sebelumnya yaitu 30 drajat [11], sehingga diperoleh persamaan sbb:

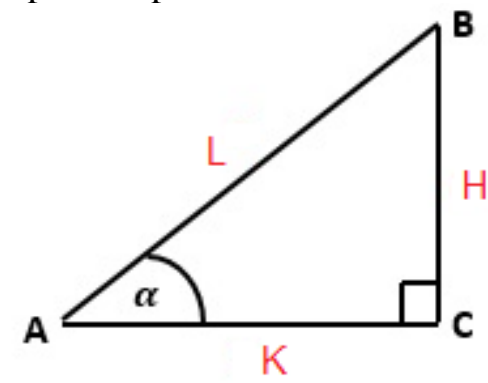

$\operatorname{Sin} \alpha=\frac{H}{L}$

$\operatorname{Sin} 30^{\circ}=\frac{1 m}{L}$

$L=\frac{1 m}{\operatorname{Sin} 30^{\circ}}$

$L=2 \mathrm{~m}$

5. Pitch turbin

Pitch turbin dirancang dengan mengambil sebuah ketetapan dari Rores yaitu sudut turbin $\leq 30^{\circ}$ dengan jarak pitch $S=1,2 \mathrm{D}$

$S=1,2 . D$

$S=1,2 \cdot 0,26 \mathrm{~m}$

$S=0,312 m$

6. Jumlah ulir

$Z=\frac{L}{S}$

$Z=\frac{2 m}{0,312 m}$

$Z=6,41=7$ ulir 
7. Sudut ulir

$$
\begin{aligned}
& X=\frac{1}{Z} x S \\
& X=\frac{1}{7} x 0,312 \\
& X=0,045 \\
& \Delta h=X . \sin 30 \\
& \Delta h=0,0225
\end{aligned}
$$

Sehingga sudut ulir didapat:

$$
\begin{aligned}
\alpha & =\frac{h_{0}}{\Delta h} \\
\alpha & =\frac{0,31}{0,0225} \\
\alpha & =13,8
\end{aligned}
$$

8. Effisiensi turbin

$$
\begin{aligned}
& \eta=\left(\frac{2 \cdot \alpha+1}{2 \cdot \alpha+2}\right) \cdot\left(1-\frac{0,01125 \cdot D^{2}}{Q}\right) \\
& \eta=\left(\frac{2 \cdot 13,8+1}{2 \cdot 13,8+2}\right) \cdot\left(1-\frac{0,01125 \cdot 0,21^{2}}{0,2}\right) \\
& \eta=96 \%
\end{aligned}
$$

\section{Daya turbin}

Dari hasil perhitungan dimensi turbin screw diatas, dapat diketahui daya turbin yang dihasilkan oleh turbin tersebut yaitu:

$$
\begin{aligned}
\mathrm{P} & =\rho \mathrm{g} \mathrm{Q} \mathrm{H} \eta \\
& =998 \mathrm{~kg} / \mathrm{m}^{3} \cdot 9,8 \mathrm{~m} / \mathrm{s}^{2} \cdot 0,2 \mathrm{~m}^{3} / \mathrm{s} \cdot 0,3 \mathrm{~m} \cdot 96 \% \\
& =563,3 \text { Watt. }
\end{aligned}
$$

10. Data hasil perancangan turbin

Table 3. Hasil perancangan turbin screw

\begin{tabular}{lll}
\hline No & Data Rancangan & Ket \\
\hline 1. & Daya Hidrolis & 612,6 Watt \\
2. & Daya Rancangan Turbin & 563,3 Watt \\
3. & Diameter Screw/Ulir & $0,213 \mathrm{~m}$ \\
4. & Diameter poros & $0,078 \mathrm{~m}$ \\
5. & Panjang Turbin & $2 \mathrm{~m}$ \\
6. & Sudut Turbin & $30^{\circ}$ \\
7. & Pitch Turbin & $0,312 \mathrm{~m}$ \\
8. & Sudut Ulir & $13,8^{\circ}$ \\
9. & Jumlah Ulir & 7 \\
10. & Effisiensi Rancangan Turbin & $96 \%$ \\
11. & Kapasitas Generator & $600 \mathrm{Watt}$ \\
12. & Material Ulir & Plat plastik \\
& & PVC $0,003 \mathrm{~m}$ \\
13. & Diameter Pully & $0,12 \mathrm{~m} ; 0,19 \mathrm{~m}$ \\
\hline
\end{tabular}
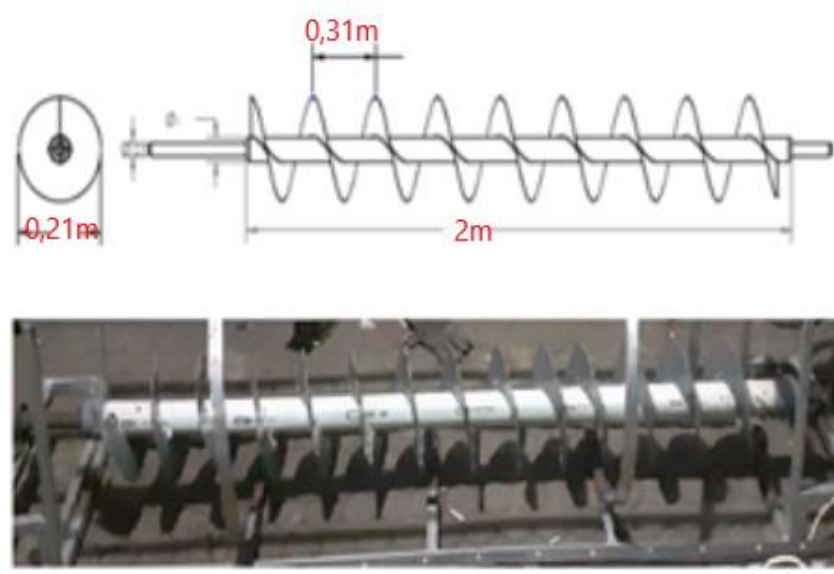

Gambar 4. Sudu turbin screw

Sudu turbin berbentuk ulir (helix) dibuat menggunakan bahan plat plastik PVC $0,003 \mathrm{~m}$. Hal ini bertujuan untuk menghindari korosi yang diakibatkat oleh reaksi oksidasi dan kavitasi turbin. Selain sudu turbin sebagian komponen turbin juga dibuat menggunakan bahan plastik PVC diantaranya poros dan cover turbin. Dimensi ulir dan panjang turbin disesuaikan dengan hasil rancangan pada tabel 3 . Diameter poros dan cover turbin dipilih menyesuaikan bahan yang tersedia di pasaran. Untuk poros menggunakan pipa pvc 2,5 inch dan untuk cover turbin menggunakan pipa pvc 10 inch. Hasil desain turbin keseluruhan dapat dilihat pada gambar 5 .

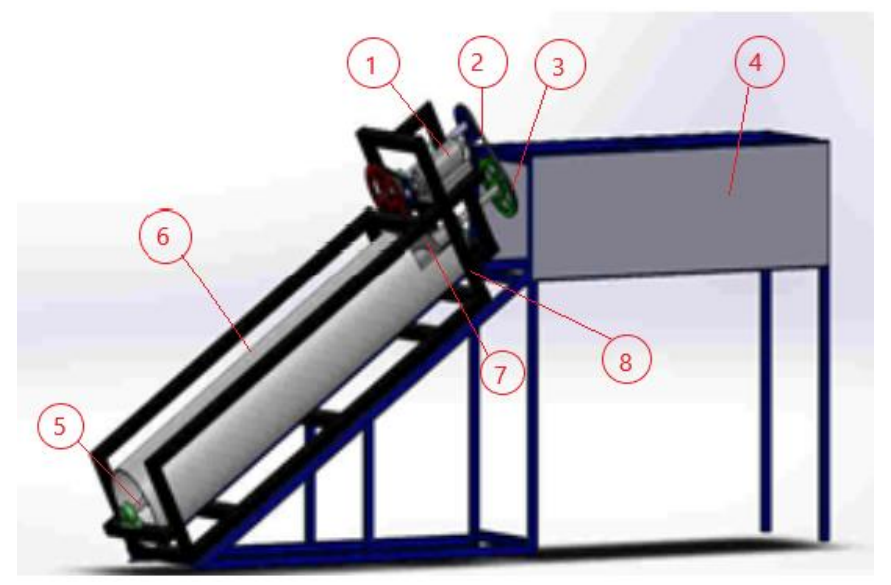

Gambar 5. Turbin screw 3D model

Keterangan gambar:
1. Generator
2. Sabuk (V-Belt)
3. Pulley
5. Poros turbin
6. Cover
7. Sudu turbin
4. Tunnel
8. Rangka turbin

\section{Pengujian turbin screw}

Pengujian turbin screw dilakukan di sungai Perumahan Puri Kedaton Desa Pematang Gajah Rt 13 provinsi Jambi. 


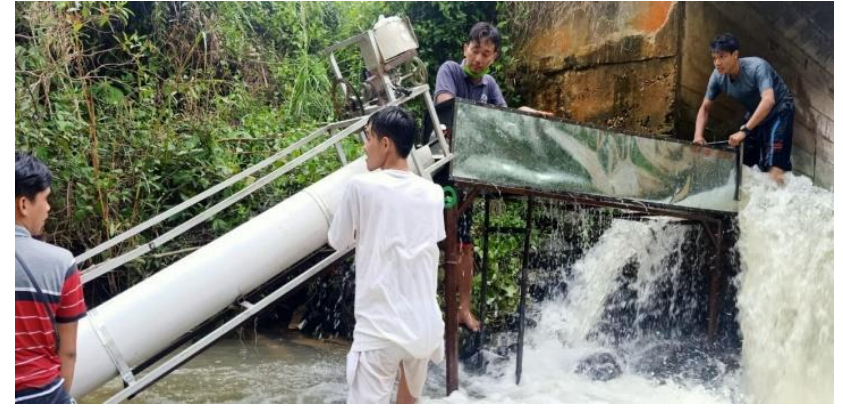

Gambar 4. Pengujian turbin screw

Pengujian dilakukan pada kondisi kecepatan air yang melewati kanal $2,3 \mathrm{~m} / \mathrm{s}$ dan debit air $0,2 \mathrm{~m}^{3} / \mathrm{s}$. Turbin dipasang pada kemiringan 30 drajat dengan memvariasikan beban putaran poros turbin $30 \mathrm{~kg}, 40 \mathrm{~kg}$, $50 \mathrm{~kg}$. Beban diatur dengan menggunakan neraca pegas digital yang dikaitkan dengan poros menggunakan sabuk. Dari pengujian yang dilakukan diperoleh torsi dan daya poros turbin sbb:

Tabel 4. Hasil pengujian turbn screw

\begin{tabular}{cccccc}
\hline $\begin{array}{c}\text { Beban } \\
(\mathrm{kg})\end{array}$ & $\begin{array}{c}\mathrm{F} \\
(\mathrm{N})\end{array}$ & $\begin{array}{c}\text { Putaran } \\
(\mathrm{rpm})\end{array}$ & $\begin{array}{c}\text { Torsi } \\
(\mathrm{N} . \mathrm{m})\end{array}$ & $\begin{array}{c}\text { Daya } \\
\text { turbin } \\
(\text { Watt })\end{array}$ & $\begin{array}{c}\text { Effisiensi } \\
(\%)\end{array}$ \\
\hline 30 & 294,3 & 1165 & 3,73 & 445 & 78,9 \\
40 & 392,4 & 654 & 4,91 & 336 & 59,6 \\
50 & 490,5 & 452 & 6,13 & 290 & 51,5 \\
\hline
\end{tabular}

Torsi dihasilkan dari gaya fluida yang mendorong sudu- sudu turbin dan diteruskan ke poros turbin. Tabel 4 menunjukkan bahwa torsi terbesar terjadi pada kondisi pembebanan $50 \mathrm{~kg}$. pada kondisi ini daya mekanik turbin mengalami peningkatan, akan tetapi putaran turbin mengalami penurunan.

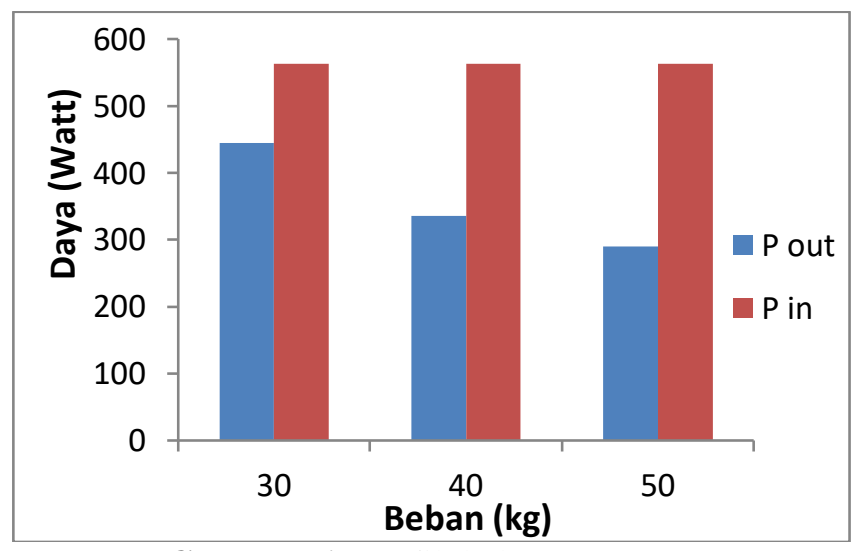

Gambar 6. Grafik beban vs Daya

Hasil pengujian menunjukkan bahwa daya mekanik turbin pada kondisi pembebanan $30 \mathrm{~kg}$ berkisar 445 Watt dengan daya masuk turbin rata - rata berkisar 563 Watt, sehingga diperoleh effisiensi tertinggi 78,9\%. Nilai ini dibawah dari nilai effisiensi perancangan yaitu $96 \%$. melebihi beberapa penelitian sebelumnya seperti penelitian yang dilakukan oleh Encu dkk, Igede dkk yang menghasilkan effisiensi turbin dibawah 20\% [12]
[13]. Kondsi ini menunjukkan bahwa hampir semua energi potensial air dapat diubah menjadi daya mekanik turbin. Selain itu cover turbin yang tertutup membuat fluida tidak keluar ketika mendorong sudu - sudu turbin pada kondisi kemiringan turbin berkisar $30^{\circ}$. Matrial turbin yang ringan juga mempengaruhi kinerja turbin tersebut sehingga gaya dorong fluida dapat diteruskan ke poros turbin dengan maksimal tanpa ada pengurangan pembebanan dari matrial turbin.

\section{SIMPULAN}

Kinerja dari sebuah turbin screw tergantung dari desain awal dan pembuatan. Perancangan disesuaikan dengan kondisi aliran sungai yang akan dipasang turbin. Beberapa parameter yang mempengaruhi kinerja turbin diantaranya dimensi sudu turbin, jarak pitch, panjang turbin, kemiringan turbin, dan matrial yang digunakan dalam pembuatan turbin. Penentuan dimensi diameter sudu turbin screw berdasarkan formulasi Rores menghasilkan dimensi optimum untuk debit air $0,2 \mathrm{~m}^{3} / \mathrm{s}$ berkisar 0,213 m dan jarak pitch 0,312 m.

Bahan plastic PVC yang digunakan pada pembuatan turbin mempunyai keunggulan yaitu lebih ringan dan terhindar korosi, akan tetapi bahan ini tidak bisa diaplikasikan untuk daya turbin sekala besar karena rentan terjadi defleksi yang berlebihan sehingga gaya dorong fluida tidak bisa sepenuhnya diterima sudu turbin.

\section{DAFTAR PUSTAKA}

[1] H. Matalata, "Listrik mikro hidro berdasarkan Potensi debit andalan sungai batanghari kota jambi," vol. 1, no. 1, pp. 1-6, 2018.

[2] F. E. Yandra and S. U. Djufri, "Studi Awal Pemanfaatan Turbin Screw pada Aliran Sungai Kecil di Kota Jambi," vol. 2, no. 1, pp. 29-32, 2019.

[3] B. Moshfegh, "World Renewable Energy Congress - Sweden Editor," 2011.

[4] A. Lashofer et al., "State of technology and design guidelines for the Archimedes screw turbine," no. March 2016, 2012.

[5] P. Taylor, G. Müller, and J. Senior, "Simplified theory of Archimedean screws Simplified theory of Archimedean screws Théorie simplifiée de la vis d 'Archimède," no. December 2014, pp. 37 41, 2010.

[6] A. T. Piper, P. J. Rosewarne, R. M. Wright, and P. S. Kemp, "The impact of an Archimedes screw hydropower turbine on fi sh migration in a lowland river," Ecol. Eng., vol. 118, no. April 2018, pp. 31-42, 2020.

[7] C. Rorres, "The Turn of the Screw: Optimal Design of an Archimedes Screw," J. Hydraul. Eng. ', pp. 72-80, 2000.

[8] A. Nurdin, P. Magister, J. T. Mesin, U. S. Maret, J. T. Mesin, and U. S. Maret, "Kajian Teoritis Uji Kerja Turbin Archimedes Screw Pada Head 
Rendah," vol. 9, no. 2, pp. 783-796, 2018.

[9] D. Adanta and M. H. G. Syafei, "Development of Archimedes Turbine Research : Review Article," pp. 177-181, 2017.

[10] J. M. C. Cengel, Yunus A., Fluid Mechanics, 4th ed. McGraw-Hill.New York. USA, 2018.

[11] Amir, "Kemiringan Optimum Model Turbin Ulir 2 Blade," J. Tek. Mesin Univ. Muhammadiyah Tangerang, vol. 2, no. 1, pp. 1-8, 2018.

[12] E. Saefudin, T. Kristyadi, M. Rifki, and S. Arifin, "Turbin Screw Untuk Pembangkit Listrik Skala Mikrohidro Ramah Lingkungan," vol. I, no. 3, pp. 233-244, 2017.

[13] I. G. W. Putra, "View of Analisa Pengaruh Tekanan Air Terhadap Kinerja PLTMH dengan Menggunakan Turbin Archimedes Screw.pdf," vol. 17, no. 3, 2018.

\section{Biodata Penulis}

Author 1,

Nama : Zainuri Anwar

TTL : Bngkinang, 16-08-1991

Alamat : Perum Cipta Bumi Mendalo, Rt 12, Desa Sungai Duren.

Pekerjaan : Dosen

Institusi : STITEKNAS Jambi

Hp : : 085274685551 